\title{
Fatigue crack propagation properties from small sized rod specimens
}

\author{
C.S. Shin*, C.Q. Cai \\ Department of Mechanical Engineering, National Taiwan University, No. 1, Sec. 4, Roosevelt Road, Taipei 10617, Taiwan, ROC \\ Received 5 August 2005; received in revised form 27 March 2006; accepted 27 March 2006
}

\begin{abstract}
Mechanical properties characterization is needed in many industrial applications yet sufficient amount of material for fabricating standard-sized testing specimens is often not available. Techniques for testing miniaturized specimen must be adopted. Much effort has been made to develop techniques for impact, fracture toughness and tensile properties of sub-sized specimens. Work on the testing of fatigue properties is more limited. In this study, fatigue crack propagation behavior is evaluated from the growth of surface crack in a cylindrical rod under tension. Rods of various lengths and diameters were tested. As the size of the rod specimen is reduced, the fatigue crack growth rate tends to increase when correlated using the stress intensity factor range. This increase is explained largely by the decrease in the degree of premature crack closure in the small specimens. Valid fatigue crack growth data can be obtained among the specimens examined except on the crack growth on the surface of the smallest specimen, which has a length of $26 \mathrm{~mm}$ and diameter of $8 \mathrm{~mm}$. Even so, valid data can still be elucidated on the latter specimen if the interior growth is considered. The dimensions of the latter specimen allow fatigue properties to be evaluated using broken remnants from impact or other test specimens.
\end{abstract}

(c) 2006 Elsevier B.V. All rights reserved.

\section{Introduction}

In nuclear pressure vessel surveillance, failure analysis and post-irradiation testing, the mechanical properties must often be characterized using a small amount of materials. Specimens are therefore commonly reconstituted from remnant parts of broken specimens. The use of a small volume of material to evaluate impact energy and fracture toughness has been widely studied (Valo and Ahlstrand, 1993; De Backer and Gutierrez-Solana, 1998; Marini et al., 1998; Tomimatsu et al., 1998; Van Walle et al., 2002). Investigations on similar applications to understand the fatigue crack propagation (FCP) are more limited. (Sriharsha et al., 1999; Li and Stubbins, 2002) Sriharsha et al. (1999) proposed the use of a modified Charpy specimen which has the same width but double the depth of a standard Charpy specimen. Li and Stubbins (2002) used very small bending specimen with dimensions $7.9 \mathrm{~mm} \times 2 \mathrm{~mm} \times 0.8 \mathrm{~mm}$. This required a high-sensitivity load measurement and control as typical loading involved was only $10 \mathrm{~N}$. Our previous work demonstrated that a cylindrical rod specimen under rotation bending may be employed to provide FCP properties. However, a certain degree

\footnotetext{
* Corresponding author. Tel.: +88622362 2160; fax: +88622362 2160 .

E-mail address: csshin@ntu.edu.tw (C.S. Shin).
}

of size effect became apparent as the specimen length or diameter was reduced. Evidence revealed that such discrepancies may be caused by premature crack closure (Shin and Chen, 2004). Monitoring crack closure under rotation bending is difficult. Moreover, it is well known that the stress state in a short beam is more complex than that in a slender long beam under bending. The latter fact may also contribute to the observed size effect. In this work, rod specimens are tested under axial tension, alleviating the complex stress state effect caused by the short beam and facilitating the monitoring of crack closure. It is hope that the results can shed some light on the possibility of using the broken halves from the impact tests for evaluating FCP properties.

\section{Experimental procedures}

Rod specimens with different lengths and diameters were machined from a $15 \mathrm{~mm}$ diameter 304 stainless steel rod stock. Table 1 presents the chemical compositions and tensile properties of the material. A specimen of length $200 \mathrm{~mm}$ and diameter $15 \mathrm{~mm}$ (designated L200 $\phi 15$ ) was chosen as the reference. For a fixed specimen length, the diameter is reduced to $10 \mathrm{~mm}$ (L200 $\phi 10)$ and $8 \mathrm{~mm}(\mathrm{~L} 200 \phi 8)$ to investigate the effect of rod diameter. Specimens of shorter lengths with the reduced diameters were also adopted. They are $50 \mathrm{~mm}$ long with a $10 \mathrm{~mm}$ 
Table 1

Chemical compositions and tensile properties of the test material

\begin{tabular}{ll}
\hline Element & Wt. $(\%)$ \\
\hline Chemical compositions & Bal. \\
$\mathrm{Fe}$ & 0.04 \\
$\mathrm{C}$ & 0.50 \\
$\mathrm{Si}$ & 1.29 \\
$\mathrm{Mn}$ & 0.33 \\
$\mathrm{P}$ & 0.00 \\
$\mathrm{~S}$ & 8.25 \\
$\mathrm{Ni}$ & 20.94 \\
$\mathrm{Cr}$ & \\
& \\
Tensile properties & 259 \\
$0.2 \%$ proof stress $(\mathrm{MPa})$ & 645 \\
Tensile strength $(\mathrm{MPa})$ & 72.9 \\
Elongation $(\%)$ & 200 \\
Young's modulus $(\mathrm{GPa})$ & \\
\hline
\end{tabular}

diameter (L50 $\phi 10)$ and $42 \mathrm{~mm}$ or $26 \mathrm{~mm}$ long with an $8 \mathrm{~mm}$ diameter (L42 $\phi 8$ and L26 $\phi 8$ ). The last specimen is sufficiently small to be machined from the broken halves of standard impact specimens. Screw threads were machined at the ends of rod specimens with lengths of $50 \mathrm{~mm}$ or less, to enable a pair of extender rods to be attached for gripping. Pilot surface was incorporated at the end of the threaded sections to ensure axial alignment. The extender rods were fabricated from high carbon tool steel to support multiple uses without significant wear. Fig. 1 shows a typical short rod specimen with the extenders.

Surface crack was created at the mid-section of each rod specimen by electric-discharge machining using a thin circular copper foil electrode. Different electrode diameters and machining depths were used to yield roughly semi-elliptical cracks with an aspect ratio ( $\mathrm{a} / \mathrm{b}$, please refer to Fig. 2 for nomenclature) of about 0.5 and higher. Before testing, all specimens were stress relieved by a solution annealing treatment in vacuum at $1050^{\circ} \mathrm{C}$ for $1 \mathrm{~h}$, followed by quick cooling in a continuous supply of argon stream.

Cyclic testing was carried out using a servo-hydraulic machine at a frequency of $15 \mathrm{~Hz}$. A constant amplitude sinusoidal waveform with a load ratio ( $\mathrm{min}$. load/max. load) of 0

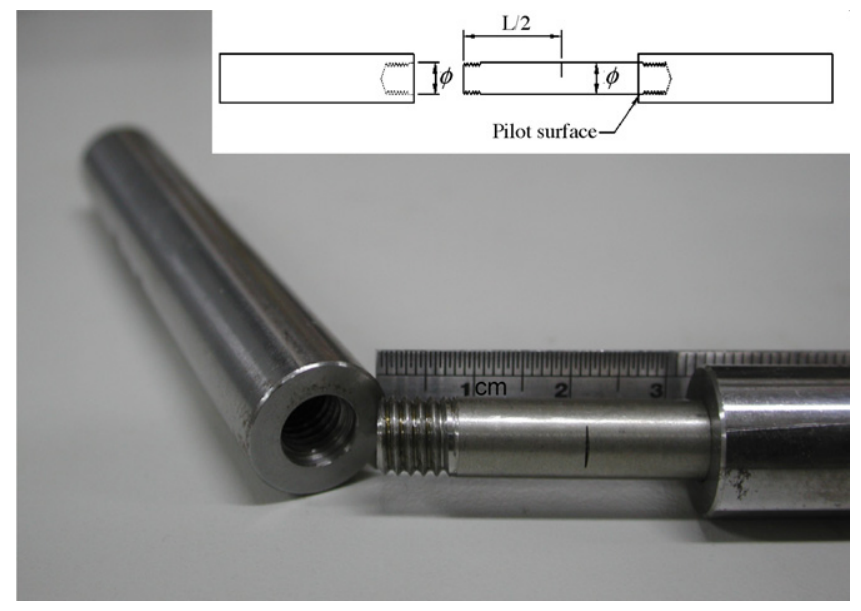

Fig. 1. A typical short rod specimen with extender rods.

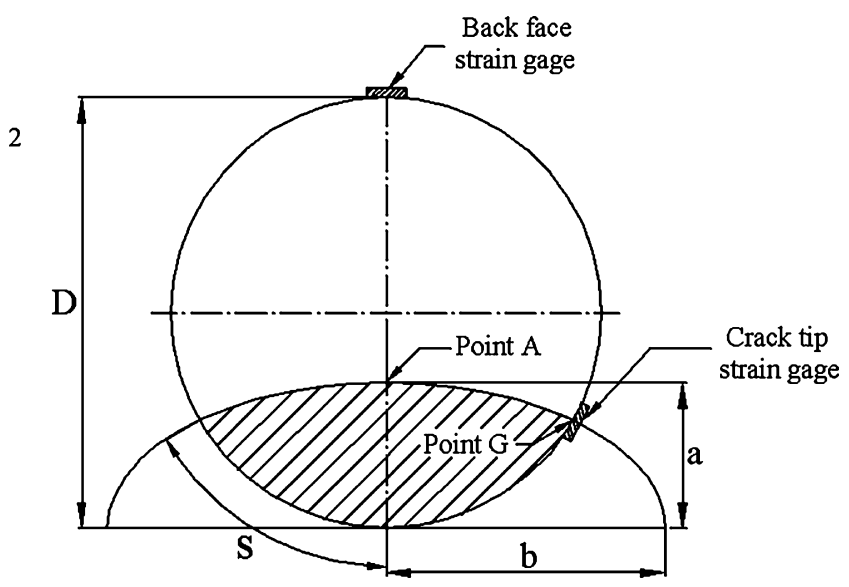

Fig. 2. Nomenclature of the surface cracked rod.

was employed. The rod specimens were tested with a pair of rigid hydraulic grips. Surface crack length was monitored using a rotary traveling microscope to a resolution of $0.026 \mathrm{~mm}$ on a $15 \mathrm{~mm}$ diameter specimen. This resolution decreases in proportion to the diameter. The crack depth and crack shape of the surface cracks were monitored with a normalized area-compliance method. Details of the approach have been reported and verified elsewhere (Shin and Cai, 2005). Essentially it involves deducing the crack shape from a combination of the crack arc-length on the rod surface and the normalized area $(\mathrm{NA}=$ area of cracked surface divided by the cross-sectional area of the rod). The normalized area is in turn deduced from the normalized back-face compliance $X$ according to the following relations:

$$
\begin{aligned}
& \text { (i) }-2.0<X \leq 0.95 \text { or } 0.04 \leq \mathrm{NA}<0.54: \\
& \mathrm{NA}=0.34167-0.174981 X-0.10034 X^{2}+2.62825 \times 10^{-2} \\
& X^{3}+0.15304 X^{4}+1.87761 \times 10^{-2} X^{5}-0.149421 X^{6} \\
& \quad-0.10801 X^{7}-2.21154 \times 10^{-2} X^{8}, \\
& \text { (ii) }-15.0<X \leq-2.0 \text { or } 0.54 \leq \mathrm{NA}<0.87: \\
& \mathrm{NA}=0.38076-9.48426 \times 10^{-2} X-9.70327 \times 10^{-3} X^{2} \\
& \quad-5.34726 \times 10^{-4} X^{3}-1.10686 \times 10^{-5} X^{4}
\end{aligned}
$$

The normalized compliance $X$ is defined as

$$
X=\frac{E}{1000} \frac{\varepsilon_{\mathrm{B}}}{\sigma}
$$

where $E$ is the Young's modulus of the specimen material, $\varepsilon_{\mathrm{B}}$ the back-face strain measured at the position as shown in Fig. 2, and $\sigma$ is the nominal stress in the rod cross section. The crack growth rates were obtained from the resulting crack length-number of cycle data using a 7-point quadratic fit method. They were correlated in terms of the corresponding stress intensity solution reported in Shin and Cai (2004).

Pre-matured crack closure invariably occurs during fatigue crack propagation. It was monitored with the widely adopted compliance technique aided with an offset method (Kikukawa et al., 1976; Fleck, 1988). Specimen compliance is measured from 


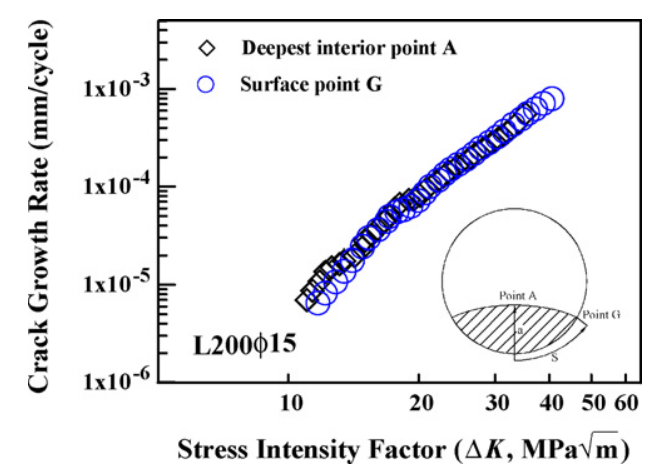

Fig. 3. Comparison between surface and interior growth in the reference specimen (L200 $\phi 15)$.

a back-face strain gage and a crack tip gage to deduce the interior and the near surface crack closure. The details and validity of this measurement have been discussed elsewhere (Shin and Cai, $2004,2005)$. The degree of crack closure is quantified by the ratio $\Delta K_{\text {eff }} / \Delta K$, where $\Delta K$ is the applied stress intensity range and $\Delta K_{\text {eff }}$ is the fraction of $\Delta K$ during which the crack stays open.

\section{Results and discussion}

\subsection{Fatigue crack growth characteristics of the reference specimens}

The reference specimen (L200 $\phi 15)$ has a length of $200 \mathrm{~mm}$. Such a length is deliberately chosen so that the crack plane is at a distance of five times the diameter from the gripped portion. This choice helps to alleviate the influence of any local non-uniform gripping stress on the development of the surface crack. Moreover, it has been shown that fatigue crack growth data from such a specimen were consistent with those collected from standard compact tension specimens (Shin and Cai, 2005). Fig. 3 compares the crack growth behavior at the surface point $\mathrm{G}$ and the deepest interior point $\mathrm{A}$ in a typical L200 $\phi 15$ specimen. Under the same stress intensity range $(\Delta K)$, crack growth rates at both positions agreed well with each other. Notably, data points obtained from the surface and from the interior at the same stress intensity range and growth rate correspond to cracks at two different instances, as crack grew with different rates at the two positions. Such agreement suggests the stress intensity factor solution and the crack length/crack shape measurement technique are appropriate for the current situation.

Under very close scrutiny, the crack propagation rate at the interior point $\mathrm{A}$ is slightly faster than that at the surface point $\mathrm{G}$, at growth rates under $2 \times 10^{-5} \mathrm{~mm} /$ cycle. This slight discrepancy may be attributed to a difference in the crack closure behaviors. Fig. 4 presents the development of crack closure at these two positions and the evolution of the surface crack shape. The initial aspect ratio of the machined crack starter notch was about 0.5 at a crack depth ratio $(a / D)$ of 0.12 . As the crack grew, the aspect ratio increased steadily to a maximum of around 0.9 at a crack depth ratio of 0.35 . Meanwhile, the degree of crack closure, $\Delta K_{\text {eff }} / \Delta K$, also increased steadily from 0.7 to 0.8 to

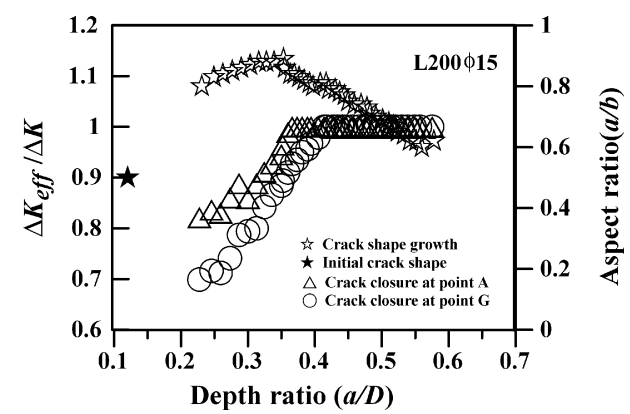

Fig. 4. Evolution of crack shape and crack closure at the surface and in the interior.

unity (i.e. crack fully open). The degree of crack closure at the surface point $\mathrm{G}$ exceeded that at the interior point $\mathrm{A}$. Around the time when the crack aspect ratio reached its maximum value, the crack became fully open at the interior point throughout the loading cycle while premature crack closure still occurred near the surface. As the crack continued to grow, it also became fully open at the surface as well when the crack depth ratio reached 0.4. Thereafter, it remained fully open throughout the loading cycle along the entire crack front. When the different closure behaviors are taken into account, the initial slight difference in crack growth data from the surface point $\mathrm{G}$ and at the deepest interior point A match each other (see Fig. 5).

The same experiment has been repeated on five rod specimens and the corresponding crack growth rate versus stress intensity range $\Delta K$ and effective stress intensity range $\Delta K_{\text {eff }}$ are shown in Fig. 6a and b, respectively. Clearly, the reproducibility of the current test procedure is acceptable. The baseline line growth rate versus $\Delta K$ and $\Delta K_{\text {eff }}$ in these reference specimens may be expressed as:

$\frac{\mathrm{d} a}{\mathrm{~d} N}=1.9 \times 10^{-9}(\Delta K)^{3.502}$

$\frac{\mathrm{d} a}{\mathrm{~d} N}=8.71 \times 10^{-9}\left(\Delta K_{\mathrm{eff}}\right)^{3.081}$

where $\mathrm{d} a / \mathrm{d} N$ is the crack growth rate in $\mathrm{mm} /$ cycle, $\Delta K$ and $\Delta K_{\text {eff }}$ are in $\mathrm{MPa} \sqrt{ } \mathrm{m}$. The coefficient of determinations for the best fit Eqs. (3) and (4) are 0.977 and 0.993 , respectively.

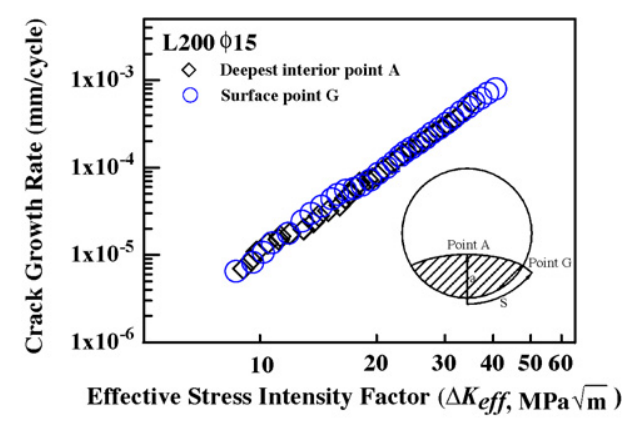

Fig. 5. Surface and interior growth rates correlated in terms of the effective stress intensity range. 


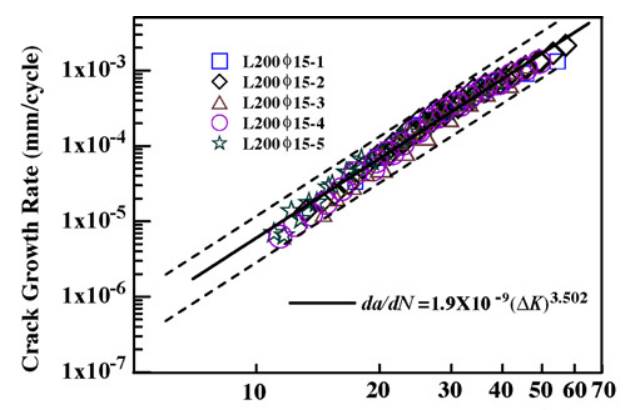

(a) Stress Intensity Factor Range $(\Delta K, \mathrm{MPa} \sqrt{\mathrm{m}})$

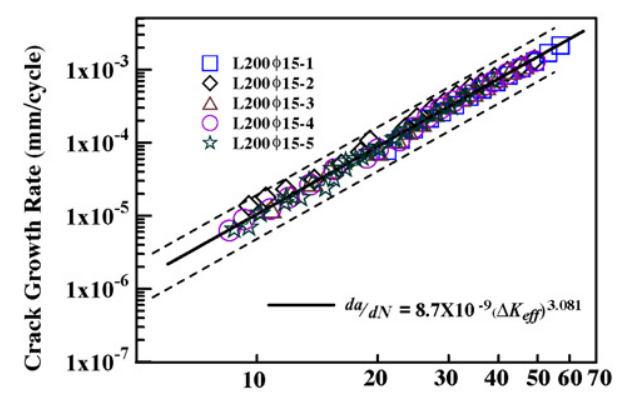

(b) Effective Stress Intensity Factor Range $\left(\Delta K_{e f f}, \mathrm{MPa} \sqrt{\mathrm{m}}\right)$

Fig. 6. Baseline fatigue crack propagation rate vs. (a) the stress intensity range $\Delta K$ and (b) the effective stress intensity range $\Delta K_{\text {eff }}$.

\subsection{Effect of rod diameter}

Rod specimens with a length of $200 \mathrm{~mm}$ and diameters of 10 and $8 \mathrm{~mm}$ were tested. Fig. 7 a plots the measured fatigue crack propagation rates for different diameter rods against the
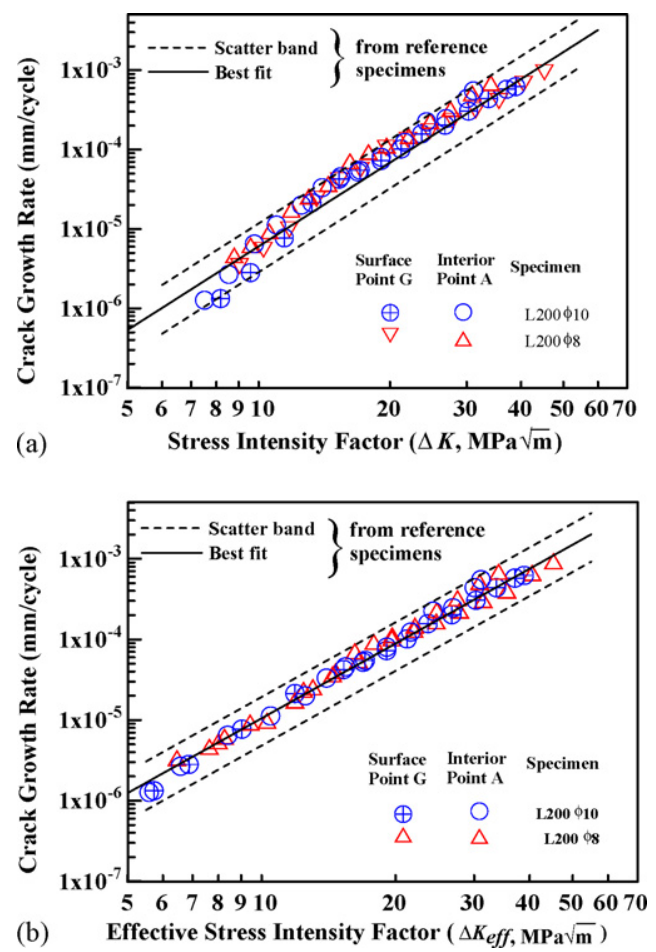

Fig. 7. Comparison of crack growth data from different sized rods in terms of (a) $\Delta K$ and (b) $\Delta K_{\text {eff }}$. applied stress intensity range. The solid line represents the Paris law fit (Eq. (3)) whereas the broken lines represent the upper and lower bounds of the scatter of the crack growth data from the reference specimens L200 $\phi 15$. The majority of growth data from the smaller rods fall within this scatter band. However, the data are not exactly centered on the best fit solid line and most of them lie between the best fit and the upper bound. To assess the deviation of the current data from the reference, an apparent coefficient of determination is computed as in a normal linear regression but with Eq. (3) taking the place of the best fit straight line. The apparent coefficient of determination in this case is 0.95 . This discrepancy may be related to a violation of the size requirement. It may also be caused by a difference in the premature crack closure behaviors, since the degrees of plasticity vary among the different sized rods. The degree of crack closure and the extent over which it occurred became smaller as the specimen diameter was decreased.

Fig. $7 \mathrm{~b}$ plots the crack growth rates for different rod specimens correlated in terms of the effective stress intensity range. Again, the solid line represents the best power law fit to the results of the reference specimens and the broken lines bound the scatter band. When crack closure is accounted for, the growth rate data of the smaller rods fall within the experimental scatter band. Moreover, the best fit straight line for the $15 \mathrm{~mm}$ diameter data is now also the best fit to the entire set of data from all the rods. The apparent coefficient of determination, as defined above but is now computed with Eq. (4) taking the place of the best fit straight line, is 0.987 . This suggests that the current rod specimen is a feasible alternative for elucidating valid fatigue crack propagation behavior in AISI 304 stainless steel.

\subsection{Effect of rod length}

Fig. 8a and $b$ plots the crack growth properties obtained from a $10 \mathrm{~mm}$ diameter rod with a reduced overall length of $50 \mathrm{~mm}$ (L50 $\phi 10)$ against $\Delta K$ and $\Delta K_{\text {eff }}$, respectively. When the growth rate is correlated in terms of $\Delta K$, the data points for growth at both the surface and the interior tend to lie above the best fit line of the reference specimens but still below the upper bound of the scatter band. When correlated in terms of $\Delta K_{\text {eff }}$, the growth data now center on the best fit line of the references. The apparent coefficients of determination are 0.967 and 0.981 , respectively. Thus the discrepancy shown in Fig. 8a is basically caused by a decrease in the degree of crack closure in the smaller specimen.

When the diameter is reduced to $8 \mathrm{~mm}$ and the specimen length is further reduced to $42 \mathrm{~mm}$, the situations are similar to that of the L50 $\phi 10$ specimen (Fig. 9a and b). Fig. 9a and b also plots the results from the smallest specimen, L26 $\phi 8$. The interior growth behavior of this specimen followed the same trends as that of the L50 $\phi 10$ and the L $42 \phi 8$ specimens. The surface growth initially followed a similar trend. However, toward the end, the growth rates lay increasingly above the upper bound of the reference scatter band (Fig. 9a). The apparent coefficient of determination for this case dropped to 0.881 . This phenomenon persisted even when the crack growth data were correlated in terms of $\Delta K_{\text {eff }}$ (Fig. 9b). The apparent coefficient of determination in the latter improved only a little bit to 0.942 . Thus this 

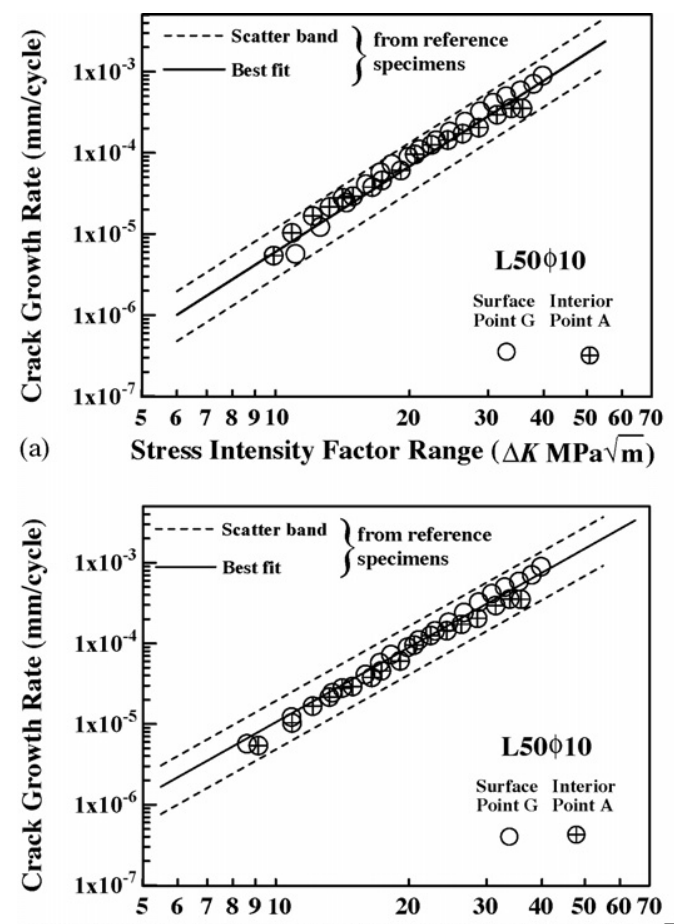

(b) Effective Stress Intensity Factor Range $\left(\Delta K_{e f f}, \mathbf{M P a} \sqrt{\mathbf{m}}\right)$

Fig. 8. Comparison of crack growth data from L50 $\phi 10$ specimen with the reference in terms of $n$ terms of (a) $\Delta K$ and (b) $\Delta K_{\text {eff }}$.

increase in growth rate cannot be accounted for by a difference in crack closure behaviors.

Prediction of the fatigue crack propagation behavior in a structure relies on the existence of a similitude between the crack

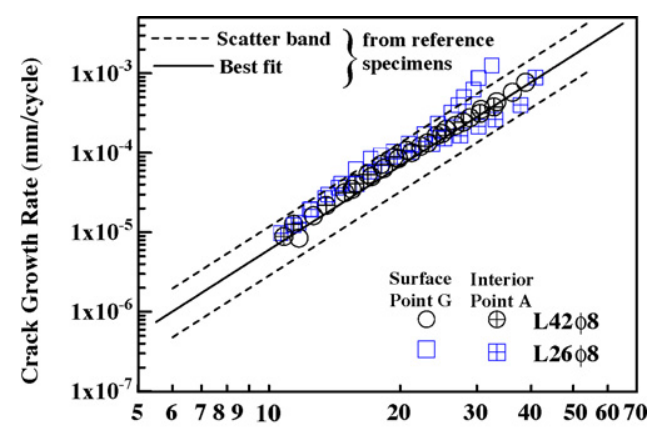

(a)

Stress Intensity Factor Range $(\Delta K \mathrm{MPa} \sqrt{\mathrm{m}})$

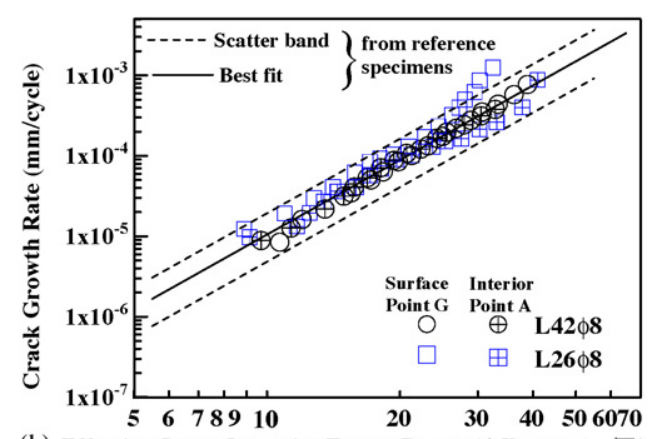

(b) Effective Stress Intensity Factor Range $\left(\Delta K_{\text {eff, }}, \mathrm{MPa} \sqrt{\mathbf{m}}\right)$

Fig. 9. Comparison of crack growth data from $\mathrm{L} 42 \phi 8$ and $\mathrm{L} 26 \phi 8$ specimens with the reference in terms of $n$ terms of (a) $\Delta K$ and (b) $\Delta K_{\text {eff. }}$. growth in the structure and that in the reference baseline situation. A major constituent of this similitude is the K-dominance in the crack tip stress field. To ensure this similitude, the ASTM E647 standards for fatigue crack propagation properties evaluation (ASTM, 1993) required the remaining ligament to be free from net section yielding and be greater than the crack tip plastic zone. In the current work, the net section stresses in all of the rods at the end of testing are slightly below the initial yield. Based on the initial yield strength, the plane stress plastic zone sizes at the end of the testing exceed the sizes of the corresponding remaining ligaments. However, the current test material strain hardens heavily. If the mean between the initial yield and the ultimate tensile strength is adopted, then all the plastic zones are within the remaining ligaments. This may explain the fact that all the $\phi 10$ data and most of the $\phi 8$ data agreed well with the data of the reference. For the smallest L26 $\phi 8$ specimen, the screw threads are very close to the crack plane and the local stress concentration there may have adverse effects on the plastic zone size. The interior of the specimen has a lower stress intensity and suffers from a higher degree of constraint. The size of the plastic zone there probably still satisfied the remaining ligament criterion. This was not the case for the surface plastic zone towards the end of the test. Thus, the initial surface growth and the entire interior growth of the L26 $\phi 8$ specimen were consistent with the reference. Towards the end, when the remaining ligament criterion was being increasingly violated, the surface growth rates deviated increasingly above the reference. Since the size requirement and the degree of plasticity depend on strength as well as the strain hardening behavior, the smallest rod size applicable in the current work may or may not be applicable in a different material. It is suggested that careful validation is needed for any specific material concerned.

Fig. 10 compares the typical development of the stress intensity factor of the current $8 \mathrm{~mm}$ diameter rod specimens herein with that of a standard compact tension specimen with a width of $50 \mathrm{~mm}$. The crack length that corresponds to the stress intensity at the deepest interior point $\mathrm{A}$ is the surface crack depth $a$ and at the surface point $\mathrm{G}$ is the surface half arc-length $s$. In all cases, the crack lengths that correspond to a starting stress intensity of $10 \mathrm{MPa} \sqrt{ } \mathrm{m}$ are taken as zero. Clearly, when the sub-sized rod specimen is used, a wider range of stress intensity is covered within a smaller crack growth increment. Thus

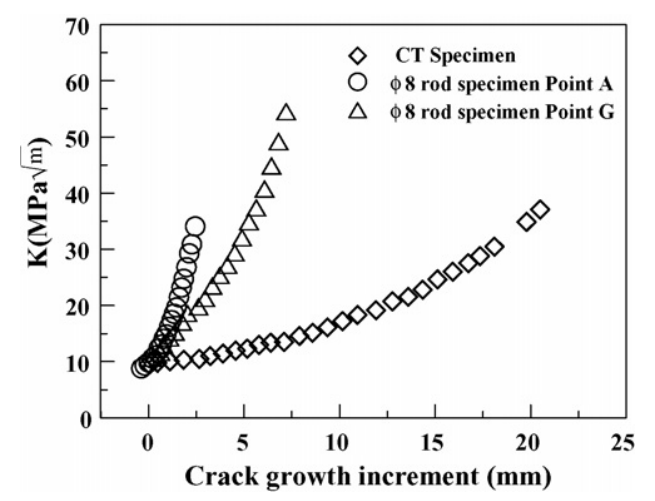

Fig. 10. Comparison of stress intensity development with crack length under constant load. 
testing using the rod specimens not only consumes less material but also significantly reduces testing time. If only the interior growth is considered, then the smallest L26 $\phi 8$ rod specimen can still provide valid results. Given the dimensions of the latter, it is possible to carry out fatigue properties evaluation with remnants from broken impact or other test specimens. Moreover, the typical loading involved is in the order of $\mathrm{kN}$ (around $6 \mathrm{kN}$ in this work) and so only a common testing system with normal accessories for testing standard specimen are needed to conduct the evaluation.

\section{Conclusions}

Cylindrical specimens with lengths from 26 to $200 \mathrm{~mm}$ and diameters from 8 to $15 \mathrm{~mm}$ were tested to obtain fatigue crack propagation data. Specimens that were longer than $42 \mathrm{~mm}$, regardless of diameter, yielded surface and interior growth data within the reference scatter band. Valid fatigue crack propagation data were obtained even when the length of the specimen was as low as $26 \mathrm{~mm}$ and the diameter was $8 \mathrm{~mm}$, when only the interior growth was considered. The latter dimensions of a specimen allowed fatigue properties to be evaluated using remnants from broken impact specimens, using only a conventional testing system for standard specimens.

\section{Acknowledgement}

The authors would like to thank the National Science Council, ROC for financial support for this work through the project NSC93-2212-E-002-062.

\section{References}

ASTM E-647-93, 1993. Standard Test Method for Constant Load Amplitude Fatigue Crack Growth Rates Above $10^{-8} \mathrm{~m} /$ cycle. American Society for Testing and Materials, Philadelphia, USA.

De Backer, F., Gutierrez-Solana, F., 1998. The effects of the configuration of a weld-reconstituted compact tension specimen on fracture toughness determination. In: Corwin, W.R., Rosinski, S.T., van Walle, E. (Eds.), Small
Specimen Test Techniques, ASTM STP 1329. American Society for Testing and Materials, pp. 513-522.

Fleck, N.A., 1988. Influence of stress state on crack growth retardation. Basic Questions in Fatigue, ASTM STP 924, pp. 157-183.

Kikukawa, M., Jono, M., Tanaka, K., 1976. Fatigue crack closure behavior at low stress intensity level. In: Proceedings of the ICM2, Boston, pp. 254277.

Li, M., Stubbins, J.F., 2002. Subsize specimens for fatigue crack growth rate testing of metallic materials. In: Sokolov, M.A., Landes, J.D., Lucas, G.E. (Eds.), Small Specimen Test Techniques: Fourth Volume, ASTM STP 1418. ASTM International, West Conshohocken, PA, pp. 321-335.

Marini, B., Carassou, S., Wident, P., Soulat, P., 1998. Evaluation of the fracture toughness of a C-Mn steel using small notched tensile specimens. In: Corwin, W.R., Rosinski, S.T., van Walle, E. (Eds.), Small Specimen Test Techniques, ASTM STP 1329. American Society for Testing and Materials, pp. 513-522.

Shin, C.S., Cai, C.Q., 2004. Experimental and finite element analyses on stress intensity factors of elliptical surface crack in a circular shaft under tension and bending. Int. J. Fracture 129, 239-264.

Shin, C.S., Cai, C.Q., 2005. A normalized area-compliance method for monitoring the surface crack development in a cylindrical rod. Int. J. Fatigue 27-7, 801-809.

Shin, C.S., Chen, P.C., 2004. Fatigue crack propagation testing using subsized rotating bending specimens. Nucl. Eng. Des. 231, 13-26.

Sriharsha, H.K., Pandey, R.K., Chatterjee, S., 1999. Towards standardizing a subsize specimen for fatigue crack propagation behavior or a nuclear pressure vessel steel. Eng. Fract. Mech. 64, 607-624.

Tomimatsu, M., Kawaguchi, S., Iida, M., 1998. Reconstitution of fracture toughness specimen for surveillance test. In: Corwin, W.R., Rosinski, S.T., van Walle, E. (Eds.), Small Specimen Test Techniques, ASTM STP 1329. American Society for Testing and Materials, pp. 470-483.

Valo, M., Ahlstrand, R., 1993. Application of reconstitution welding technique for studying base metal of a Novovoronesh Unit-1 trepan sample. In: Corwin, W.R., Haggag, F.M., Server, W.L. (Eds.), Small Specimen Test Techniques Applied to Nuclear Reactor Vessel Thermal Annealing and Plant Life Extension, ASTM STP 1204. American Society for Testing and Materials, pp. 440-456.

Van Walle, E., Scibetta, M., Valo, M.J., Viehrig, H.-W., Richter, H., Atkins, T., Wootton, M.R., Keim, E., Debarberis, L., Horsten, M., 2002. RESQUE: reconstitution techniques qualification and evaluation to study ageing phenomena of nuclear pressure vessel materials. In: Sokolov, M.A., Landes, J.D., Lucas, G.E. (Eds.), Small Specimen Test Techniques: Fourth Volume, ASTM STP 1418. ASTM International, West Conshohocken, PA, pp. 409454. 